\title{
Public Awareness of Ischemic Stroke in Medina city, Kingdom of Saudi Arabia
}

Majed M. Alluqmani, MD, FRCPC, Nada R. Almshhen, MBBS, Rawan A. Alotaibi, MBBS, Omaymah Y. Aljardi, MBBS, Heba M. Zahid, PhD.

\begin{abstract}
الأهداف : تقييم مستوى الوعي بالسكتة الدماغية لدى المواطنين السعوديين في المدينة المنورة .

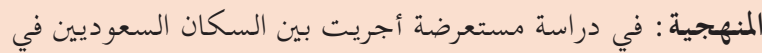

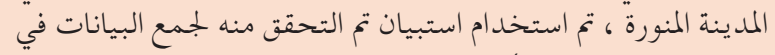

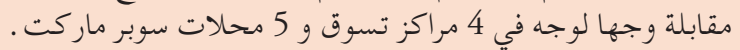

النتائج : كان العدد الإجمالي للمشاركين الذين أكملوا الاستبيان

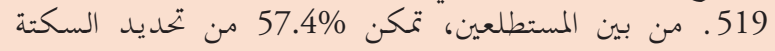

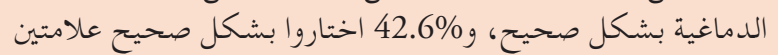

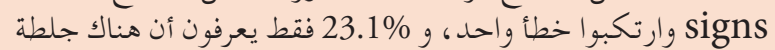

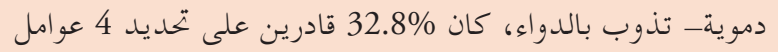

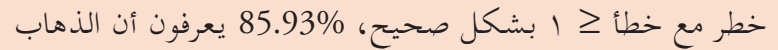
إلى الطوارئ ER هو الإِجراء المناسب، و و

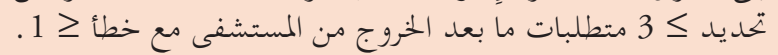

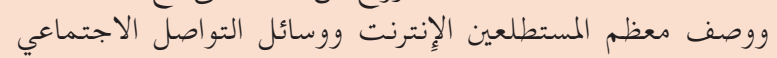

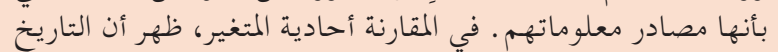
العائلي للسكتة (0.001) الانحار 40

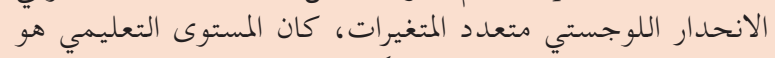

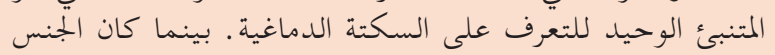

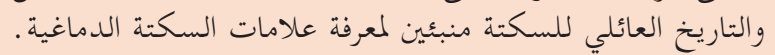

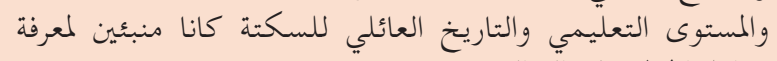

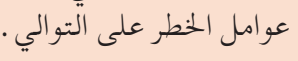

المخلاصة : هناك نقص كبير في معرفة السكتة الدماغية لدى سكان سكان

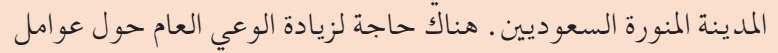

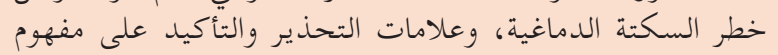

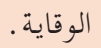

Objectives: To assess social awareness of ischemic stroke amongst Saudi citizens in Medina city.

Methods: In a cross-sectional study conducted between February and September 2019, we used a validated questionnaire to conduct face-to-face interviews and collect data, at 4 shopping malls and 5 supermarkets in Medina city, KSA.

Results: Five hundred and nineteen participants completed the questionnaire. Of the respondents, $57.4 \%$ correctly defined stroke, $42.6 \%$ correctly chose $\geq 2$ stroke signs and made $\leq$ one mistake, $23.1 \%$ knew of blood clot-dissolving drugs, $32.8 \%$ correctly identified $\geq 4$ risk factors with $\leq$ one mistake, $85.93 \%$ knew that going to the Emergency Room (ER) was the correct action, and $35.84 \%$ identified $\geq 3$ postdischarge requirements, with $\leq$ one mistake. Most participants $(65.77 \%)$ cited internet and social media as information sources. In the univariate comparison, older age $(p<0.001)$ and family history of stroke $(p=0.001)$ better predicted stroke knowledge. In a multivariate logistic regression, the only predictor for stroke recognition was the educational level. The gender and family history were predictors for stroke signs knowledge. Educational level and the family history of stroke were predictors for risk factors knowledge respectively.

Conclusion: We observed a significant stroke knowledge deficit in our Saudi cohort, thus there is a need to increase public awareness about stroke risk factors, warning signs and emphasizing prevention approaches.

Neurosciences 2021; Vol. 26 (2): 134-140 doi: 10.17712/nsj.2021.2.20200105

From the Department of Internal Medicine (Alluqmani), College of Medicine, from Taibah College of Medicine (Almshhen, Alotaibi, Aljardi), from College of Applied Medical Sciences (Zahid), Department of Medical Laboratories Technology, Taibah University, Medina, Kingdom of Saudi Arabia.

Received 10th October 2020. Accepted 28th June 2020.

Address correspondence and reprint request to: Dr. Majed M. Alluqmani, Department of Internal Medicine, College of Medicine, Taibah University, Medina, Kingdom of Saudi Arabia. E-mail:Mloqmani@hotmail.com

ORCID ID: https://orcid.org/0000-0002-54166247 
$\mathrm{I}_{\mathrm{sin}}^{\mathrm{sin}}$ schemic stroke is caused by an interrupted blood supply to the brain, due to either a thrombotic or embolic event. This event cuts off oxygen and nutrients, causing damage to brain tissue. ${ }^{1}$ Stroke is the second most common cause of death after heart disease, and the leading cause of approximately $11.3 \%$ of total deaths worldwide. ${ }^{2}$ In 2010 , its global prevalence was 33 million. ${ }^{3}$ In the Middle East region, it is forecasted that stroke mortality will approximately double by $2030 .{ }^{4}$ In the Kingdom of Saudi Arabia (KSA), the stroke prevalence is 29 individuals per 100,000 per annum, ${ }^{5}$ and is a major social and economic medical problem afflicting that country. ${ }^{6}$

Stroke results in physical, psychological and social functional impairments, ending in long term disability and mortality. ${ }^{7}$ Several risk factors have been identified as the most common causes of stroke in Saudi Arabia; ${ }^{8}$ they include hypertension, dyslipidemia, obesity, and diabetes mellitus are major risk factors for stroke and might be considered as critical factors for primary and secondary prevention of stroke. Importantly, $80 \%$ of stroke cases can be prevented with proper risk factor knowledge;" such actions can lead to early hospitalization and improved stroke prognoses and survival rates, ${ }^{3}$ thus social awareness is key to preventing stroke and/or improving outcomes.

In the KSA, stroke ranks second in the top ten causes of death. ${ }^{10}$ In a 2017 study in Riyadh city, researchers measured knowledge and attitudes to stroke. The authors determined stroke information sources and assessed their reliability, and found inadequate knowledge on stroke symptoms and causes. ${ }^{11}$

Lack of awareness about stroke was found to be a major cause of the high incidence of stroke in the Middle East, as awareness about risks can help in the primary prevention of the disease. ${ }^{12}$ This study therefore assessed awareness levels of ischemic stroke, including risk factors, warning signs and therapeutic options in Saudi citizens in Medina City.

Methods. Study design and timeframe. This study was a cross-sectional analysis of a convenient sample taken from a population in Medina city, Kingdom of Saudi Arabia. This study was conducted between February and September 2019.

Disclosure. Authors have no conflict of interests, and the work was not supported or funded by any drug company.
Study population. Saudi citizens living in Medina city aged between 20 and 65 years were included. The study participants were 521 participants from 4 different shopping malls who underwent face-to-face interviews to assure the validation. All participants with previous stroke diagnosis were excluded.

Sampling methodology. The sample size was determined using the OpenEpi ${ }^{13}$ for infinite populations, hypothesizing a $50 \% \pm 5 \%$ level of awareness at a confidence level of $95 \%$. This yielded a sample size of at least 384 participants, which were recruited from four shopping malls and 5 supermarkets across Medina City. Three trained medical students administered an interviewer-administered questionnaire. The questionnaire included a first section including items about demographic characters and personal and family history of stroke. The second section included items on ischemic stroke knowledge including a question about stroke definition in the form of "what is an ischemic stroke". This section also included items on stroke signs, risk factors, management, information sources and awareness of thrombolytic agents. The questionnaire was approved by a neurologist. Questions were asked in a list format in Arabic. A pilot study was conducted in 20 participants to avoid any misunderstanding of any questionnaire item.

Data analysis. Data was analyzed by the Statistical Package for Social Sciences $\left(\mathrm{IBM}^{\circ}\right.$ SPSS $^{\bullet}$ Statistics for Windows, Version 26.0. Armonk, NY: IBM Corp). Descriptive data was presented as numbers and frequencies, and the chi-squared test was applied to assess relationships between variables. Multivariate logistical regression analysis was used to examine the effects of gender, educational level and a relative's previous diagnosis knowledge on recognition of stroke definition, stroke signs and stroke risk factors. A $p<0.05$ value was considered statistically significant. Additionally, adjusted odd ratio with $95 \%$ confidence interval was reported.

Ethical considerations. Ethical approval was provided by the college of medicine research ethical committee at Taibah University, Medina, Kingdom of Saudi Arabia (No.: IRB00010413). Consent was obtained from all participants after the study aims were explained.

Results. Respondent demographic characteristics are described (Table 1). Only 57.4\% of respondents correctly defined ischemic stroke as blockage of the blood flow to the brain. However, $15.6 \%$ believed it was heart disease, $5.8 \%$ selected a brain tumor, and $21.2 \%$ did not know the answer. As for participants' characters, 
Public Awareness of Ischemic Stroke ... Alluqmani et al

Table 1 - Demographic characteristics of respondents.

\begin{tabular}{|c|c|c|c|}
\hline Variables & A & B & Chi-squared test (p-value) \\
\hline & & & \\
\hline $\mathrm{n}(\%)$ & $298(57.4)$ & $221(42.6)$ & \\
\hline Gender & & & \\
\hline Male & $113(53.6)$ & $98(46.4)$ & $2.17(0.14)$ \\
\hline Female & $185(60)$ & $123(40)$ & \\
\hline Age, years & & & \\
\hline$<40$ & $260(57)$ & $196(43)$ & $1.004(0.65)$ \\
\hline$\geq 40$ & $38(60.3)$ & $25(39.7)$ & \\
\hline Educational Level & & & \\
\hline High school and less & $60(49.5)$ & $61(50.4)$ & $3.93(0.05)$ \\
\hline Higher education & $238(59.8)$ & $160(40.2)$ & \\
\hline Occupation & & & \\
\hline Unemployed & $122(59.22)$ & $84(40.77)$ & $27.5(<0.001)$ \\
\hline Non-medical field student & $46(51.11)$ & $44(48.88)$ & \\
\hline Medical field student & $32(88.88)$ & $4(11.11)$ & \\
\hline Non-health care professional & $68(46.57)$ & $78(53.42)$ & \\
\hline Health care professional & $30(73.17)$ & $11(26.82)$ & \\
\hline Relative's previous diagnosis & & & \\
\hline Yes & $61(59.8)$ & $41(40.2)$ & $0.296(0.6)$ \\
\hline No & $237(56.83)$ & $180(43.17)$ & \\
\hline
\end{tabular}

Table 2 - Knowledge of stroke signs and correct behavior with suspected stroke.

\begin{tabular}{|c|c|c|c|}
\hline Variables & A & B & Total $519(\%)$ \\
\hline $\mathrm{n}(\%)$ & $298(57.4)$ & $221(42.6)$ & \\
\hline \multicolumn{4}{|l|}{ Stroke Signs } \\
\hline Mouth deviation & $145(48.65)$ & $70(31.67)$ & $215(41.42)^{*}$ \\
\hline Speech difficulty & $217(72.81)$ & $114(51.58)$ & $331(63.77)^{*}$ \\
\hline Focal weakness & $168(56.37)$ & $79(35.74)$ & $247(47.6)^{*}$ \\
\hline Chest pain & $49(16.44)$ & $56(25.33)$ & $105(20.23)^{*}$ \\
\hline Shortness of breath & $108(36.24)$ & $72(32.57)$ & $180(34.68)^{*}$ \\
\hline Identified $\geq$ two stroke signs with $\leq$ one mistake & $155(52.01)$ & $66(29.86)$ & $221(42.58)$ \\
\hline \multicolumn{4}{|l|}{ Behavior with suspected stroke } \\
\hline Go to ER & $264(88.6)$ & $182(82.35)$ & $446(85.93)$ \\
\hline Call 937 & $31(10.4)$ & $35(15.84)$ & $66(12.72)$ \\
\hline Stay at home & $0(0.00)$ & $4(1.8)$ & $4(1.8)$ \\
\hline Use alternative medicine & $1(0.33)$ & $0(0)$ & $1(0.33)$ \\
\hline Go to the pharmacy & $2(0.67)$ & $0(0)$ & $2(0.67)$ \\
\hline Awareness of blood clot-dissolving drugs & $85(28.52)$ & $35(15.84)$ & $120(23.12)$ \\
\hline Knowledge of correct timeframe in which to administer blood clot-dissolving drugs & $44 / 85(51.76)$ & $14 / 35(40)$ & $58 / 120(48.33)$ \\
\hline
\end{tabular}

Table 3 - Knowledge of stroke risk factors.

\begin{tabular}{lccc}
\hline Variables & A & B & Total 519 (\%)* \\
\hline $\mathrm{n}(\%)$ & $298(57.4)$ & $221(42.6)$ & $340(65.5)$ \\
Hypertension & $222(74.5)$ & $118(53.4)$ & $109(21)$ \\
Diabetes & $69(23.15)$ & $40(18.1)$ & $171(32.94)$ \\
Smoking & $110(36.9)$ & $61(27.6)$ & $175(33.72)$ \\
Dyslipidemia & $116(38.9)$ & $59(26.69)$ & $105(20.23)$ \\
Obesity & $69(23.15)$ & $36(16.29)$ & $212(40.85)$ \\
Stress & $138(46.3)$ & $74(33.48)$ & $206(39.7)$ \\
Heart disease & $125(41.94)$ & $8(36.65)$ & $65(1.43)$ \\
Asthma & $15(5.03)$ & $20(9.05)$ & $652)$ \\
Iron deficiency anemia & $45(15.1)$ & & $170(32.75)$ \\
Identified & & $54(24.43)$ & \\
$\geq 4$ stroke risk factors with $\leq 1$ mistake & $116(38.92)$ & & \\
\hline
\end{tabular}

A - recognized stroke definition, B - did not recognize stroke definition, ${ }^{*}$ Multiple choice questions, thus it does not constitute $100 \%$ 
Table 4 - Knowledge of post-discharge requirements.

\begin{tabular}{lccc}
\hline Variables & A & B & Total 519(\%)* \\
& $298(57.4)$ & 221 (42.6\%) & \\
\hline Control chronic disease & $170(57.04)$ & $80(36.2)$ & $250(48.17)$ \\
Smoking cessation & $140(47)$ & $73(33.03)$ & $213(41.04)$ \\
Physiotherapy & $132(44.3)$ & $63(28.5)$ & $195(37.57)$ \\
Walking & $172(57.7)$ & $90(40.72)$ & $262(50.48)$ \\
Treat iron-deficiency anemia & $48(16.1)$ & $26(11.76)$ & $74(14.26)$ \\
Cauterization & $19(6.37)$ & $12(5.43)$ & $31(6)$ \\
Identified & & & $186(35.84)$ \\
$\geq 3$ post-discharge requirements with $\leq 1$ mistake & $135(45.30)$ & $51(23.07)$ & \\
\hline A - recognized stroke definition, B - did not recognize stroke definition, ${ }^{*}$ Multiple choice questions, thus it does not constitute $100 \%$
\end{tabular}

Table 5 - Source of information.

\begin{tabular}{lccc}
\hline Variables & A & B & $\begin{array}{c}\text { Total } \\
519(\%)^{*}\end{array}$ \\
& $298(57.4)$ & $221(42.6)$ & \\
\hline Internet & $196(65.77)$ & $130(58.82)$ & $326(62.81)$ \\
Social media & $104(35)$ & $94(42.53)$ & $198(38.15)$ \\
Leaflets & $64(21.48)$ & $45(20.36)$ & $109(21)$ \\
TV & $42(14.1)$ & $36(16.3)$ & $78(15.03)$ \\
Previous knowledge & $14(4.7)$ & $4(1.8)$ & $18(3.47)$ \\
Family experience & $5(1.7)$ & $8(3.62)$ & $13(2.5)$ \\
Friends & $13(4.36)$ & $5(2.26)$ & $18(3.47)$ \\
Physicians & $5(1.7)$ & $1(0.45)$ & $6(1.15)$ \\
\hline \multicolumn{2}{l}{ A - recognized stroke definition, B - did not recognize stroke definition, } \\
\multicolumn{4}{r}{ *Multiple choice questions, thus it does not constitute 100\% } \\
\hline
\end{tabular}

medical field students and health care professionals had a significant higher percent of those who had recognized stroke definition. On the other hand, a non-significant difference was found according to participants' gender, age, educational level and relative's previous diagnosis.

Most respondents (63.8\%) identified speech difficulty as a sign of stroke. Focal weakness was identified by $47.6 \%$, followed by mouth deviation by $41.4 \%$. Shortness of breath and chest pain were chosen by $34.7 \%$ and $20.2 \%$, respectively. The general knowledge of stroke signs, defined by identifying $\geq 2$ signs with $\leq$ one mistake, revealed that $42.6 \%$ of respondents had a good knowledge. However, only $23.1 \%$ were aware of blood clot-dissolving drugs, and almost half recognized the correct time frame, within which this drug should be administered (Table 2).

The majority of respondents (88.6\%) knew that going to the emergency room (ER) was the correct course of action. However, $12.72 \%$ believed calling the free medical help line, 937 was appropriate (Table 2).

Hypertension and stress were the most frequently cited stroke risk factors, at $65.5 \%$ and $40.85 \%$, respectively. This was followed by heart disease at $39.7 \%$, dyslipidemia at $33.72 \%$ smoking at $32.94 \%$, obesity at $20.23 \%$ and diabetes at $21 \%$. General knowledge of stroke risk factors, as defined by identifying $\geq 4$ risk factors with $\leq$ one mistake, revealed that $32.8 \%$ had a good knowledge of these factors (Table 3 ).

Only $35.84 \%$ identified $\geq 3$ post-discharge requirements with $\leq$ one mistake. Half of respondents identified walking (57.7\%) and chronic disease management $(57.04 \%)$ as important post-discharge necessities. Stopping smoking and implementing physiotherapy were chosen by $41 \%$ and $37.57 \%$, respectively (Table 4). Internet and social media were ranked the most frequent sources of information on stroke (Table 5).

Overall, 111 participants identified $\geq 2$ stroke signs with $\leq$ one mistake, $\geq 4$ stroke risk factors with $\leq$ one mistake, and $\geq 3$ post-discharge requirements with $\leq$ one mistake. This represented $21.3 \%$ of respondents.

Participants with an age of $\geq 40$ years and those having a relative with a previous stroke diagnosis had a significantly higher level of knowledge $(p \leq 0.05)$. However, gender and educational level did not have an impact on the overall knowledge $(p>0.05)$ (Table 6).

In a multivariate logistic regression analysis, for stroke recognition, the only predictor was the educational level (OR=1.6, [95\% CI=1.03-2.4], $p=0.034)$. However, for the stroke sign knowledge, the gender and the family history were predictors $(\mathrm{OR}=1.6,[95 \% \mathrm{CI}=1.2-2.9]$, $p=0.013$ and $\mathrm{OR}=1.8,[95 \% \mathrm{CI}=1.2-2.9], p=0.009$ ) respectively. Educational level and the family history of stroke were predictors for the risk factor knowledge $(\mathrm{OR}=1.7,[95 \% \mathrm{CI}=1.1-2.7], p=0.028$ and $\mathrm{OR}=1.6$, [95\% CI=1.03-2.6], $p=0.036$ ) respectively (Table 7).

Discussion. This community-based study investigated basic levels of public knowledge on stroke definition, risk factors, symptoms and treatments. When respondents were asked about the definition of ischemic stroke, $57.4 \%$ defined ischemic stroke correctly, as 
Table 6 - Relationship between participants' demographic characters and their total knowledge regarding signs, risk factors, and post-discharge requirement of stroke.

\begin{tabular}{|c|c|c|c|c|}
\hline \multirow[t]{2}{*}{ Variables } & \multicolumn{2}{|c|}{ n (\%) } & \multirow{2}{*}{$\begin{array}{l}\text { Chi -squared } \\
\text { test }\end{array}$} & \multirow[t]{2}{*}{$P$-value } \\
\hline & $67 / 519(13)$ & $452 / 519(87)$ & & \\
\hline \multicolumn{5}{|l|}{ Gender } \\
\hline Male & $28(13.3)$ & $183(86.7)$ & 0.041 & 0.839 \\
\hline Female & $39(12.7)$ & $269(87.3)$ & & \\
\hline \multicolumn{5}{|l|}{ Age, years } \\
\hline$<40$ & $50(11)$ & $406(89)$ & \multirow{2}{*}{12.634} & \multirow[b]{2}{*}{$<0.001$} \\
\hline $\begin{array}{l}\geq 40 \\
\text { Educational Level }\end{array}$ & $17(27)$ & $46(73)$ & & \\
\hline Less than higher education & $13(10.7)$ & $108(89.3)$ & \multirow{2}{*}{0.658} & \multirow{2}{*}{0.417} \\
\hline Higher education and above & $54(13.6)$ & $344(86.4)$ & & \\
\hline \multicolumn{5}{|l|}{ Relative's previous diagnosis } \\
\hline Yes & $23(22.5)$ & $79(77.5)$ & \multirow{2}{*}{10.492} & \multirow{2}{*}{0.001} \\
\hline No & $44(10.6)$ & $373(89.4)$ & & \\
\hline
\end{tabular}

Table 7 - Multivariant logistic regression involving characteristic data as independent variables to predict stroke definition knowledge, signs knowledge and risk factors knowledge (dependent variables).

\begin{tabular}{|c|c|c|c|}
\hline Independent variables & OR & $95 \% \mathrm{CI}$ & $P$-value \\
\hline \multicolumn{4}{|c|}{ Stroke definition knowledge } \\
\hline Educational level & 1.6 & $1.03-2.4$ & 0.034 \\
\hline \multicolumn{4}{|l|}{ Stroke signs knowledge } \\
\hline Gender & 1.6 & $1.2-2.9$ & 0.013 \\
\hline Family history & 1.8 & $1.2-2.9$ & 0.009 \\
\hline \multicolumn{4}{|l|}{ Risk factors knowledge } \\
\hline Educational level & 1.7 & $1.1-2.7$ & 0.028 \\
\hline Family history & 1.6 & $1.03-2.6$ & 0.036 \\
\hline
\end{tabular}

blockage of the blood flow to the brain. This was similar to a study in Riyadh, were $64 \%$ chose the correct stroke definition, ${ }^{14}$ whereas in an Omani study, only $24.8 \%$ of respondents stated the correct definition. ${ }^{15}$ In this study, $15.6 \%$ believed stroke was a heart disease, $5.8 \%$ chose a brain tumor, and $21.2 \%$ did not know the answer.

Eighty percent of stroke cases are preventable 9; the key is recognizing and taking action towards modifiable risk factors. ${ }^{16}$ The general knowledge of stroke risk factors, as defined by identifying $\geq$ four risk factors with $\leq$ one mistake, revealed that $32.8 \%$ of respondents had a good knowledge of stroke risk factors (Table 3).

In this study, hypertension was identified as a stroke risk factor by $65.5 \%$ of respondents. This was similar to other community-based studies in Jordan and Riyadh, where $56 \%$ and $74 \%$ of respondents identified hypertension as a risk factor, respectively. ${ }^{11,17}$ However, in older Riyadh and Omani studies, only 30\% and 34.5\% of respondents identified hypertension as a risk factor, respectively. ${ }^{14,15}$ This increased knowledge difference could reflect increased exposure to the internet.

While diabetes is a burden disease and highly prevalent in the KSA, it was identified by only $21 \%$ of respondents. This observation was similar to other studies in Riyadh, ${ }^{14}$ Gulf Cooperation Council Countries, ${ }^{18}$ Oman ${ }^{15}$ and Jordan, ${ }^{17}$ where diabetes recognition as a stroke risk factor was relatively low. Other risk factors such as heart disease, dyslipidemia, smoking and obesity were identified by $<50 \%$ of respondents, which was reflected in other studies. ${ }^{14,17,19}$ Recognizing stroke warning signs could impact on timing access to medical emergency services, thereby improving stroke prognoses and increased survival times. ${ }^{8}$ The general knowledge of stroke signs, as defined by identifying $\geq 2$ signs with $\leq$ one mistake, revealed that only $42.6 \%$ of respondents had this knowledge level.

The most commonly identified sign of stroke was speech difficulty, as cited by the Riyadh study. ${ }^{14}$. This contrasted with other studies where focal weakness was listed as the most common stroke sign. ${ }^{17,20}$ In our study, focal weakness was stated by $47.6 \%$ of respondents, followed by mouth deviation by $41.4 \%$. Shortness of breath and chest pain were chosen by $34.7 \%$ and $20.2 \%$, respectively. These answers indicated a confusion between heart attacks and stroke, which agreed with other studies. ${ }^{14,21}$ Respondents with a family history of stroke had increased knowledge of stroke signs; this was expected as family members circulated stroke information during conversations about ill relatives.

When respondents were asked about the correct actions in responding to stroke signs, the majority responded that going to the ER was the right action (Table 2). However, only $23.1 \%$ answered yes when 
asked if they ever heard of "blood clot dissolving drugs". This was similar to an Australian study where only $21.0 \%$ of respondents knew about such drugs, ${ }^{21}$ while in an Indian study, only $7.4 \%$ knew about such drugs. ${ }^{20}$ In our study, almost half of respondents who knew about drug availability, recognized the correct time frame within which the medication should be administered.

Approximately $13 \%$ of respondents believed calling the health line, 937 was appropriate when dealing with stroke signs. This raised the question about how well the public know about health line services, and that stroke was not one of them.

It is reasonable to evaluate public knowledge about post-discharge requirements, as they are important for stroke recovery and the prevention of further stroke attacks. Only $35.84 \%$ of respondents identified $\geq 3$ post-discharge requirements with $\leq$ one mistake. Half of respondents identified walking and chronic disease management as an important post-discharge necessity. Stopping smoking and implementing physiotherapy were chosen by $41 \%$ and $37.57 \%$, respectively (Table 4 ).

When respondents were asked about information sources regarding stroke knowledge, the internet and social media were ranked the highest. Therefore, exploiting social media in awareness campaigns could increase public knowledge of different health issues, not just stroke.

We observed that participants with an age of $\geq 40$ were significantly higher in identifying $\geq 2$ stroke signs with $\leq$ one mistake, $\geq 4$ stroke risk factors with $\leq$ one mistake, and $\geq 3$ post-discharge requirements with $\leq$ one mistake. (Table 6). However, in a previous Riyadh study being $\leq 45$ of age had a higher level of knowledge. ${ }^{14}$

Respondents with a family history of stroke were significantly higher in identifying $\geq 2$ stroke signs with $\leq$ one mistake, $\geq 4$ stroke risk factors with $\leq$ one mistake, and $\geq 3$ post-discharge requirements with $\leq$ one mistake. This agreed with previous studies where having a family history of stroke was an independent predictor of increased subject knowledge..$^{21,22}$

Awareness about stroke symptoms can lead to early start of medical treatment and this will lead to avoiding permanent damage and complications. That is why there is a need to ensure satisfactory public awareness. ${ }^{23}$ Assessment of the population awareness regarding this critical disease will help to understand the level of awareness and the need of public health education program to reach the required level of knowledge thus, decreasing the incidence of disease and limiting its complications and improving the public quality of life.
Study limitations. Our study was subjected to several limitations. The first was the relatively small sample size compared to other Saudi studies. ${ }^{14}$ The second limitation was using a questionnaire that may have a recall bias. These factors may have resulted in an overestimation of the public's knowledge of stroke.

Conclusions. Our study assessed knowledge levels of stroke in a Medina population. Our data showed that approximately $42 \%$ of respondents had an adequate knowledge of the definition of stroke, its risk factors, symptoms and acute treatments. However, there is a need for increased public awareness of stroke risk factors, warning signs and stroke prevention. Life style modifications and chronic disease control are important factors, and should be included in educational programs. These may be in the format of national programs, potentially exploiting social media and TV modalities. This study calls for further research to comprehensively investigate stroke awareness, including larger samples in rural populations.

Acknowledgements. The authors gratefully thank the Scientific Research Ethics Committee, Taibah University, College of Medicine, and Proof Reading Service for English language editing.

\section{References}

1. Grotta J, Albers GW, Broderick JP, Kasner SE, Lo EH, Mendelow AD, et al. Stroke, Pathophysiology, Diagnosis and Management. 6th Ed. Elsevier; 2016.

2. World Health Organization (WHO). The top 10 causes of death 2018 Available from: https://www.who.int/news-room/ fact-sheets/detail/the-top-10-causes-of-death

3. Mozaffarian D, Benjamin EJ, Go AS, Arnett DK, Blaha MJ, Cushman M, et al. Heart disease and stroke statistics - 2015 update. Circulation 2015; 131: e29-e322.

4. Tran J, Mirzaei M, Anderson L, Leeder SR. The epidemiology of stroke in the Middle East and North Africa. J Neurol Sci 2010; 295: 38-40.

5. Robert AA, Zamzami MM. Stroke in Saudi Arabia: a review of the recent literature. Pan Afr Med J 2014; 17: 14-19.

6. Al-Jadid MS, Robert AA. Determinants of length of stay in an inpatient stroke rehabilitation unit in Saudi Arabia. Saudi Med J 2010; 31: 189-92.

7. Dhamoon MS, McClure LA, White CL, Lakshminarayan K, Benavente OR, Elkind MS; SPS3 Investigators. Long-term disability after lacunar stroke: secondary prevention of small subcortical strokes. Neurology 2015; 10; 84: 1002-1008.

8. Alharbi MN, Alharbi AK, Alamri MA, Alharthi AA, A Alqerafi AM, Alharbi MN. Ischemic stroke: prevalence of modifiable risk factors in the Saudi population. IJMDC 2019; 3: 601-603.

9. CDC. Preventing Stroke Deaths. 06 September 2017 [cited 202020 June]; Available from: https://www.cdc.gov/vitalsigns/ stroke/index.html

10. World Health Organization (WHO). Saudi Arabia: top 10 causes of death. 2017. https://www.worldlifeexpectancy.com/ news/saudi-arabia-vs-egypt-top-10-causes-of-death 
11. Al Otaibi MK, Al Otaibi FF, Al Khodair YO, Falatah EM, Al Mutairi HA. Knowledge and attitude of stroke among Saudi population in Riyadh, Kingdom of Saudi Arabia. IJASR 2017; 5: 149-157.

12. Al Zahrani FM, Al Amri AA, Al Shehri JA. Awareness of Stroke among Teachers in Asser Region, Saudi Arabia. Prensa Med Argen 2019; 105: 4-9.

13. Dean AG, Sullivan KM, Soe MM. OpenEpi: Open Source Epidemiologic Statistics for Public Health, Version. www. OpenEpi.com [Updated 6 April 2013; Accessed 15 June 2020]

14. Alaqeel A, Al Ammari A, Al Syefi N, Al-Hussain F, Mohammad Y. Stroke awareness in the Saudi community living in Riyadh: prompt public health measures must be implemented. J Stroke and Cerebrovasc 2014; 23: 500-504.

15. Al Shafaee MA, Ganguly SS, Al Asmi AR. Perception of stroke and knowledge of potential risk factors among Omani patients at increased risk for stroke. BMC Neurology 2006; 6: 38.

16. Boehme AK, Esenwa C, Elkind MS. Stroke Risk Factors, Genetics, and Prevention. Circ Res 2017; 120: 472-495.

17. Madae'en S, Bulatova N, Al-Qhewii A, Sakran L, El-Zayyat H, Kamar M, et al. Stroke awareness in the general population: a study from Jordan. Trop J Pharm Res 2014; 12: 1071.
18. Kamran S, Bener AB, Deleu D, Khoja W, Jumma M, Al Shubali A, et al. The level of awareness of stroke risk factors and symptoms in the Gulf cooperation council countries: Gulf cooperation council stroke awareness study. Neuroepidemiology 2007; 29: 235-242.

19. Lu S, Bao MY, Miao SM, Zhang X, Jia QQ, Jing SQ, et al. Prevalence of hypertension, diabetes, and dyslipidemia, and their additive effects on myocardial infarction and stroke: a cross-sectional study in Nanjing, China. Ann Transl Med 2019; 7: 436-448.

20. Pandian JD, Jaison A, Deepak SS, Kalra G, Shamsher S, Lincoln DJ, et al. Public awareness of warning symptoms, risk factors, and treatment of stroke in northwest India. Stroke 2005; 36: 644-648.

21. Yoon SS, Heller RF, Levi C, Wiggers JE. Fitzgerald PE. Knowledge of stroke risk factors, warning symptoms, and treatment among an Australian urban population. Stroke 2001; 32: 1926-1930.

22. Vincent-Onabajo G, Moses T. Knowledge of stroke risk factors among stroke survivors in Nigeria. Hindawi Publishing Corporation Stroke Research and Treatment 2016; 1-5.

23. El-Hajj M, Salameh P, Rachidi S, Hosseini H . The epidemiology of stroke in the Middle East. Eur Stroke J 2016; 1: 180-198.

\section{Authorship entitlement}

Excerpts from the Uniform Requirements for Manuscripts Submitted to Biomedical

Journals updated November 2003.

Available from www.icmje.org

The international Committee of Medical Journal Editors has recommended the following criteria for authorship; these criteria are still appropriate for those journals that distinguish authors from other contributors.

Authorship credit should be based on 1) substantial contributions to conception and design, or acquisition of data, or analysis and interpretation of data; 2) intellectual content; and 3) final approval of the version to be published. Authors should meet conditions 1,2 , and 3 .

Acquisition of funding, collection of data, or general supervision of the research group, alone, does not justify authorship.

An author should be prepared to explain the order in which authors are listed. 